\title{
Reinforcing effect of polyurethane sizing on properties of acrylonitrile-butadiene-styrene composites involving short carbon fiber
}

\author{
Shan Abdulalaziz Ahmed ${ }^{1}$. Seha Tirkes ${ }^{1}\left[\right.$ ] Umit Tayfun $^{2}$ (1)
}

Received: 9 June 2020 / Accepted: 30 October 2020 / Published online: 19 November 2020

(c) Springer Nature Switzerland AG 2020

\begin{abstract}
In this study, we present the influence of sizing layer of short carbon fiber (CF) to the basic properties of CF reinforced acrylonitrile-butadiene-styrene (ABS) composites. Composite samples are prepared with four different loading ratio of 5 , 10,15 and $20 \%$ by weight using melt-compounding. Surface topography, elemental analysis and surface functionality of CF samples are confirmed by atomic force microscopy (AFM), energy-dispersive X-ray (EDX) and infrared (FTIR) spectroscopy techniques, respectively. Characterizations of composites are performed based on mechanical, thermo-mechanical, melt-flow (MFI) and morphological performances of composites. According to test results, mechanical properties of $A B S$ are enhanced with CF additions. Polyurethane (PU) sized CF containing composites display higher tensile strength, modulus and hardness compared to desized ones. CF additions lead to increase in glass transition temperature of ABS copolymer. MFI values of composites are found to be in narrow range, hence CF additions cause no effect for processing conditions of ABS. According to SEM analysis, CF surfaces are covered by polymer matrix thanks to PU sizing layer of CF, whereas debondings are formed for desized CF-filled ABS matrix. Results indicate that PU-sizing is suitable for ABS/CF composite system.
\end{abstract}

\section{Graphical Abstract}

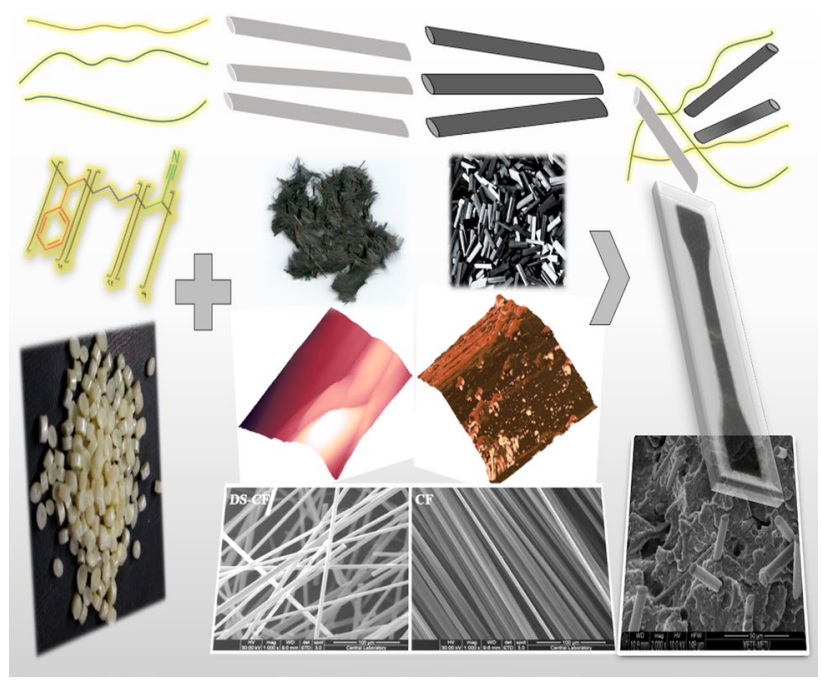

Umit Tayfun, umit.tayfun@inovasens.com | ${ }^{1}$ Department of Chemical Engineering, Atilim University, 06836 Ankara, Turkey. ${ }^{2}$ Inovasens Ltd, Izmir Technopark, 35430 Izmir, Turkey. 
Keywords Acrylonitrile-butadiene-styrene $\cdot$ Carbon fiber $\cdot$ Sizing layer $\cdot$ Fiber reinforced polymer composites $\cdot$ Melt mixing

\section{Introduction}

Carbon fiber reinforced polymer composites have great attention and have found various use in many application areas including transportation, construction, electronics, aerospace and defense industry. The main goal of its usage is the reduction of weight by replacing metal parts with carbon fiber containing polymeric structures [1, 2]. Research efforts and application fields based on carbon fiber and its composites are continued to grow steadily and they are considered to advanced materials in many topics [3-5].

Acrylonitrile-butadiene-styrene (ABS) terpolymer is a trendy candidate among all of the polymers thanks to expansion in its commercial use for additive manufacturing field recently. The structure of ABS copolymer is composing of polybutadiene groups dispersed in styrene and acrylonitrile parts. Polybutadiene is the elastomeric unit whereas styrene and acrylonitrile show thermoplastic behavior. These phases are responsible for mainly the toughness, dimensional stability and chemical resistance properties of ABS copolymer [6-8]. Research studies have been conducted to optimize and tune of basic properties of ABS copolymer in order to extent its effective use in numerous applications in a wide array of industrial fields including mostly additive manufacturing and automotive [9-12].

There have been several research studies that conducted on short CF containing thermoplastic composites in the literature. Anguita et al. developed dimensionally ultra-stable CF-reinforced polymeric structures for their specific applications for satellites in a recent study. They stated that near-zero in thermal expansion coefficient was reached for dimensionally stable CF-filled composite structures [13]. They observed that reinforcing capability of CF was mainly depending on adhesion between the fibers and polymer matrix. In another study, Dike produced short CF filled polyamide (PA) composites with different surface coated CF samples. He reported that composites involving isocyanate coated CF displayed the highest enhancement based on the mechanical properties of PAbased composites [14]. According to study reported by Aparna et al., tensile strength of polypropylene (PP)-PA blend exhibited remarkable increase after short CF inclusion [15]. Duchoslav et al. performed surface sizings for CF samples. They found that deterioration occur in sizing layer of CF surface during processing stage of composite manufacturing [16]. Rezaei et al. investigated that short CF addition caused improvement on strength and stiffness of
PP/CF composites [17]. In a recent study, Park et al. demonstrated that thermal stability and tensile behavior of PP/CF composite system were enhanced by applying irradiation [18]. Savas et al. studied the effect of CF addition to PPbased composites [19]. They observed that elastic modulus of PP was extended with the increase in CF content. Nie and his coworkers fabricated CF reinforced poly(vinylidene fluoride) (PVDF) composites in order to examine their wear resistance [20]. According to their findings, PVDF exhibited the highest tribological performance with $20 \%$ CF inclusion. Pinpathomrat et al. performed the production of CFfilled PA composites by fused deposition modeling and they found that CF donated UV resistance for PA matrix [21]. Jiang et al. performed CF containing polyurethane (PU)-based composites. They proved that surface coating of CF caused remarkable increase on tensile strength of composites [22].

Short CF reinforced ABS-based composites were also studied in the literature. Investigations of these composites mostly dealt with the mechanical performance. Love et al. fabricated short CF loaded ABS composites and they displayed that tensile strength and modulus of $A B S$ raised with the addition of CF $[23,24]$. Yang et al. stated that $10 \%$ filling ratio of CF caused remarkable increases for flexural and tensile strength values of ABS [25]. Huang et al. investigated that $C F$ addition to $A B S$ results in improvement for strength and modulus values of neat ABS [26]. Hull et al. showed that processing conditions of $A B S$ filaments are significantly affected by CF content in the case of 3D printing applications [27]. Quan et al. demonstrated that short CF loaded ABS filaments can be optimized for the manufacturing of composite parts using fused deposition modelling [28]. According to research works regarding polycarbonate-ABS blends conducted by Lee et al. and Baek et al., CF incorporations led to increase in tensile strength and elastic modulus values of blends on the contrary reduction in impact resistance [29]. Ning et al. fabricated $C F$ reinforced $A B S$ composites using additive manufacturing process. They postulated that porosity of $3 \mathrm{D}$ printed parts yields reductions on mechanical properties of composites [30].

The objective of this study is to investigate the effect of surface sizing and amount of CF to properties of ABS-based composites. The presented results reflect the potential use of $A B S$ in wide range of areas including additive manufacturing, transportation, construction and aerospace applications. In the light of related research highlights, the role of polyurethane layer on CF to the properties of ABS/CF composite system was 
Table 1 Process parameters of composites

\begin{tabular}{lrl}
\hline Parameter & Specification & Unit \\
\hline Processing temperature & 230 & ${ }^{\circ} \mathrm{C}$ \\
Mixing time & 5 & $\mathrm{~min}$ \\
Screw speed & 100 & $\mathrm{rpm}$ \\
Barrel temperature & 240 & ${ }^{\circ} \mathrm{C}$ \\
Mold temperature & 50 & ${ }^{\circ} \mathrm{C}$ \\
Injection pressure & 8 & $\mathrm{bar}$ \\
Holding time & 3 & $\mathrm{~min}$ \\
\hline
\end{tabular}

postulated first time with this study. For this purpose, desized and PU-sized chopped CFs were compounded with ABS copolymer using melt-blending process. Meltmixing technique was used for preparation of composites since this processing method is widely applied in industrial fields. This method is also providing similar processing methodology with additive manufacturing technology. Surface covering of CF samples was visualized using atomic force microscopy (AFM), energydispersive X-ray spectroscopy (EDX) and infrared spectroscopy (FTIR) test techniques. Characterizations of composite samples were performed based on the effect of sizing layer on fiber and concentration of CF. Basic properties of composites including mechanical, thermomechanical, melt flow and morphological behaviors were reported in order to provide information for material researchers to produce ABS-based composites with required parameters. The article is organized by the explanation of materials, composite fabrication and characterization methods followed by the brief discussion based on the test data and conclusion remarks are indicated according to findings in the final section.

\section{Experiment set-up}

\subsection{Materials}

In this study, ABS was used as polymer matrix and short $C F$ samples were used as reinforcing agent. ABS copolymer was purchased as chip form by Lanxess, Cologne, Germany. It has the trade name of Lustran ABS M203FC. CF samples were supplied from Dowaksa, Yalova, Turkey under the commercial name of Aksaca AC 0101. It has chopped form with $3 \mathrm{~cm}$ length. This $C F$ grade has density of $1.76 \mathrm{~kJ} / \mathrm{m}^{2}$, diameter of $7 \mu \mathrm{m}$ and surface covering of polyurethane with the sizing ratio of $1.5-2.0 \%$. Mechanical properties of CF sample are cited by producer as tensile strength of 4.2 $\mathrm{GPa}$, percent elongation of $1.8 \%$ and modulus of $240 \mathrm{GPa}$. Commercially sized CF was annealed at $450{ }^{\circ} \mathrm{C}$ for $4 \mathrm{~h}$ that it would be possible to the removal of sizing layer and this desized CF sample was named as DS-CF.

\subsection{Composite preparation}

ABS copolymer and CF samples were dried at $100^{\circ} \mathrm{C}$ for a period of $2 \mathrm{~h}$ to avoid possible moisture before compounding. Composites were fabricated by laboratory scale twin screw extruder (MC $15 \mathrm{HT}$, Xplore Instruments BV, Netherlands). CF samples were incorporated at four different compositions of $5,10,15$ and $20 \%$ by weight in $A B S$ matrix. ABS and composite samples obtained from extrusion process were shaped using laboratory scale injection molding instrument (Micro-injector, Daca Instruments, USA). Test specimens were shaped as standard dog-bone sample during injection molding process in accordance with ASTM D-638 standard. Test samples have dimensions of $7.6 \times 2.0 \times 80 \mathrm{~mm}^{3}$. Gauge length of dog-bone shaped test specimen is $50 \mathrm{~mm}$. Processing parameters applied during production of composites are listed in Table 1.

\subsection{Characterization techniques}

Fourier transformed infrared spectroscopy (FTIR) analysis was applied for short CF samples in attenuated total reflectance (ATR) mode using IR-spectrometer of Bruker VERTEX 70 (Massachusetts, USA). The analysis was

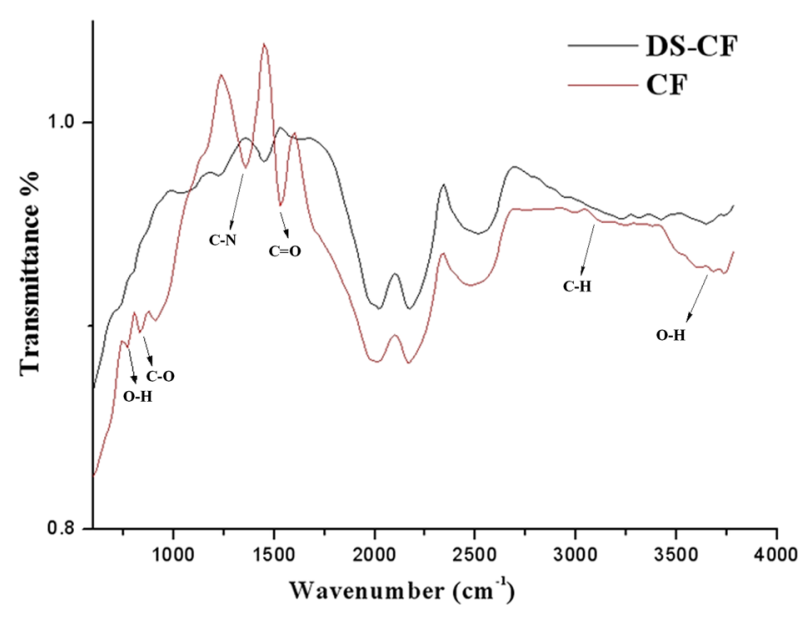

Fig. 1 FTIR spectra of CF samples

Table 2 EDX data of CF samples

\begin{tabular}{llll}
\hline Samples & CWt\%/At\% & OWt $\% /$ At $\%$ & N Wt $\% /$ At $\%$ \\
\hline DS-CF & $96.93 / 97.68$ & $3.07 / 2.32$ & $0 / 0$ \\
CF & $92.59 / 94.33$ & $7.41 / 5.67$ & $2.53 / 2.22$ \\
\hline
\end{tabular}



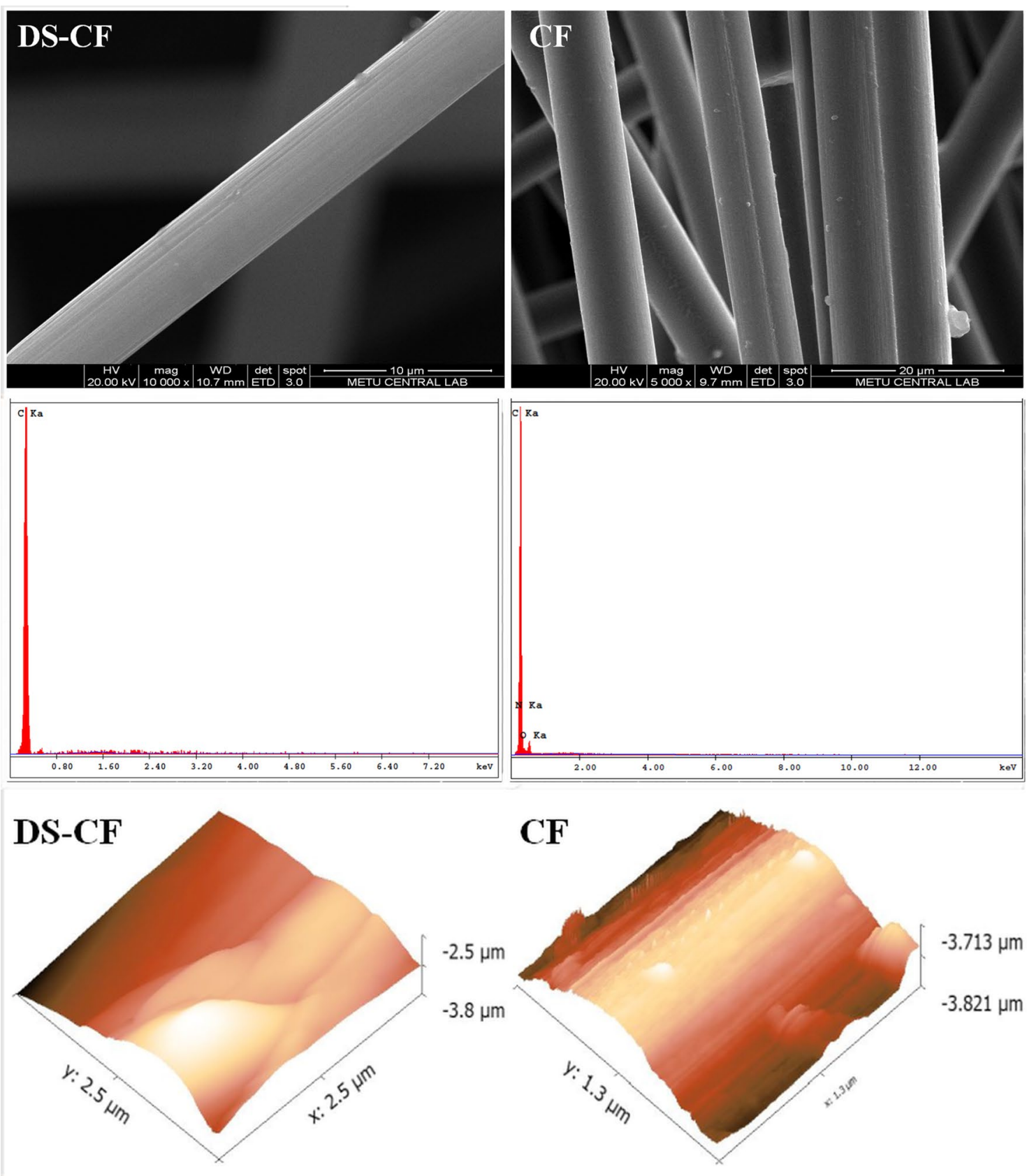

Fig. 2 SEM and AFM images and EDX data of CF samples

carried out in the wavenumber range between 600 and $3800 \mathrm{~cm}^{-1}$ at a resolution of $2 \mathrm{~cm}^{-1}$ with 32 scans. JSM6400 (JEOL Ltd, Tokyo, Japan) scanning electron microscope (SEM) was utilized to visualize the morphological properties of composites. The surfaces of fractured test samples obtained from the impact test were coated with the thin layer of gold for the aim of creating conductive surfaces. Chemical compositions of CF surfaces were evaluated using energy dispersive $\mathrm{X}$-ray spectroscopy (EDX) mode of SEM equipment. Topographical characterization of CF surface was examined by Nanosurf AFM device (Liestal, Switzerland). Tensile test measurements of ABS and composites conducted using Instron 5565A (Buckinghamshire, England) tensile testing machine with the accordance of ASTM D-638 standard. Crosshead speed of $5 \mathrm{~mm} / \mathrm{min}$ and $5 \mathrm{kN}$ load cell were applied. 

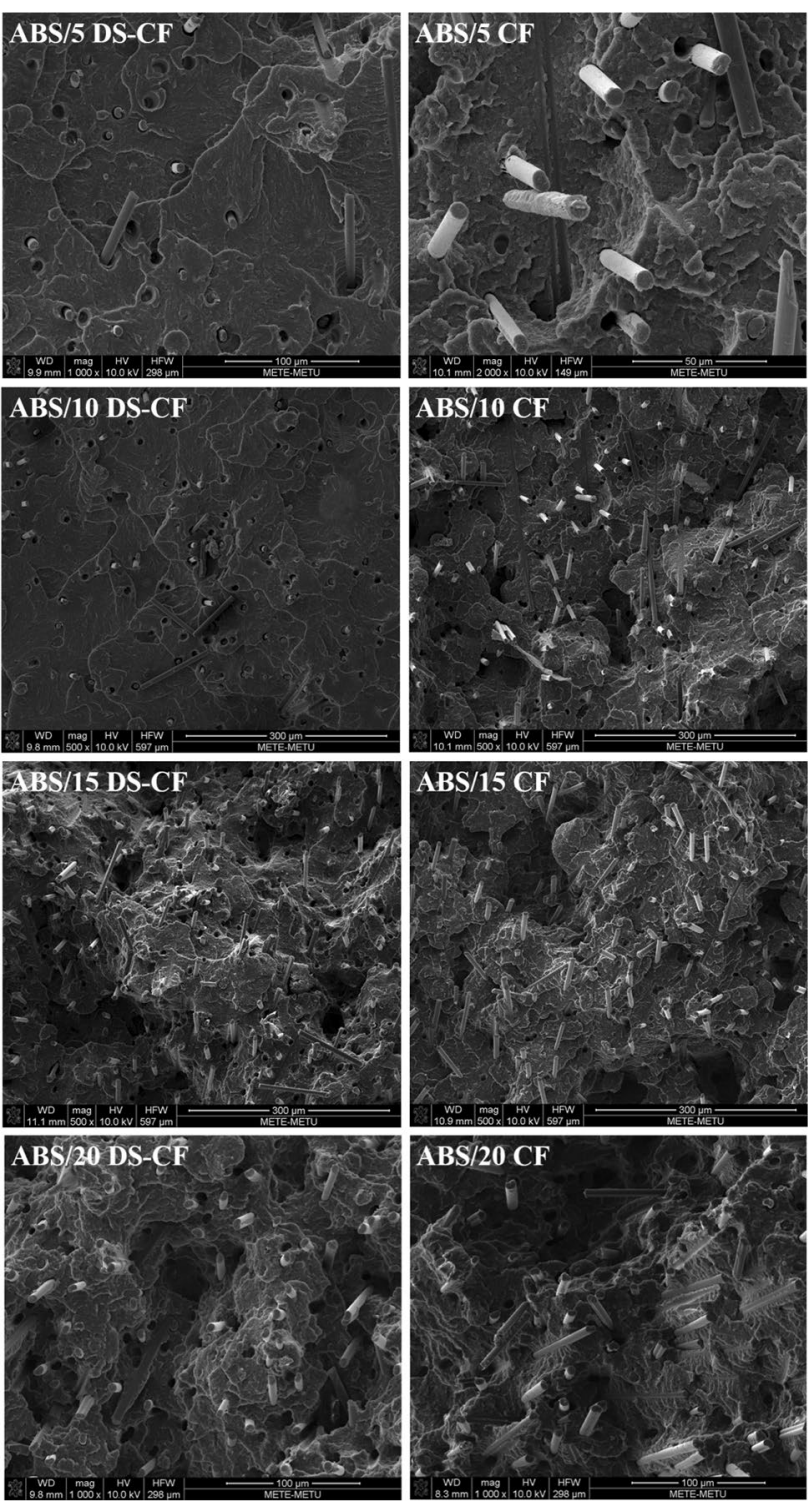

Fig. 3 SEM micrographs of composites

Tensile strength, elongation at break and tensile modulus parameters were recorded as an average of minimum five samples The un-notched lzot impact test was carried out with Coesfeld Material impact tester (Dortmund, Germany). Impact energy measurements were done according to ASTM D256 standard using a $4 \mathrm{~J}$ pendulum. Recorded values represent an average value of at least five samples with standard deviations. DMA studies were performed with DMA 8000 (Perkin Elmer, Massachusetts, USA) dynamic mechanical thermal analyser. Test specimens obtained from injection molding with dimensions of $7.6 \times 2.0 \times 50 \mathrm{~mm}^{3}$ were subjected to DMA
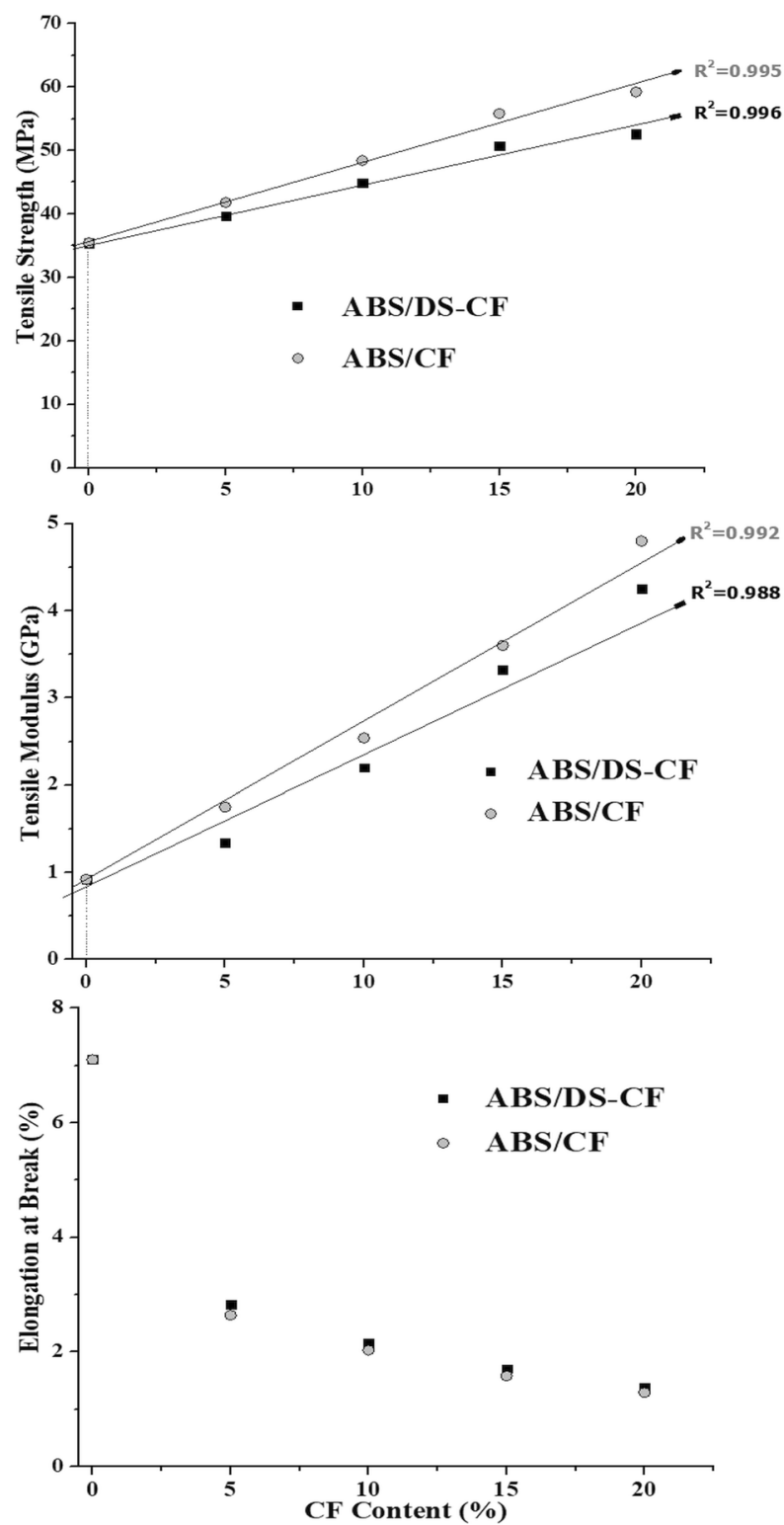

Fig. 4 The variations of tensile parameters with respect to $C F$ amount

test in dual cantilever bending mode at the temperature range from -120 to $140^{\circ} \mathrm{C}$ with $1 \mathrm{~Hz}$ constant frequency and heating rate of $5{ }^{\circ} \mathrm{C} / \mathrm{min}$. Melt-flow index (MFI) measurements were conducted using melt flow indexer (Coesfield Meltfixer LT, Dortmund, Germany) equipment. Tests were done under a standard load of $2.16 \mathrm{~kg}$ at the processing temperature of $A B S$ and composites $\left(230^{\circ} \mathrm{C}\right)$. MFI values of each sample were calculated as an average value of at least eight samples with standard deviations. 


\section{Results and discussion}

\subsection{Surface characteristics of CF samples}

Figure 1 represents the IR spectra of CF and DS-CF samples. Absorption peaks around $3000 \mathrm{~cm}^{-1}$ are attributed to $\mathrm{C}-\mathrm{H}$ vibrations of hydrocarbon groups. The characteristic peaks of hydroxyl group can be seen at 3600 and $800 \mathrm{~cm}^{-1}$ which are stem from the vibrations of $\mathrm{O}-\mathrm{H}$ bending and $\mathrm{O}-\mathrm{H}$ stretching, respectively [31,32]. These oxygen-related peaks are present for sized CF sample whereas they cannot be seen for DS-CF sample. The two peaks located near to $1000 \mathrm{~cm}^{-1}$ are stem from the $\mathrm{C}-\mathrm{O}$ vibrations. Additionally, absorption bands can be seen at nearly 1300 and $1700 \mathrm{~cm}^{-1}$ which correspond to $\mathrm{C}-\mathrm{N}$ and $\mathrm{C}=\mathrm{O}$ stretching vibrations [33, 34]. These characteristic peaks are owing to nitrile and carboxyl groups of isocyanate unit regarding PU cover on CF surface which are absent for DS-CF sample. The difference between the surfaces of two CF samples are confirmed by these findings.

Elemental compositions of CF surface supplied by EDX analysis data are listed in Table 2 and EDX spectra are shown in Fig. 2. The oxygen content of PU sized CF was found to be higher than that of DS-CF by the factor of 2.4. This sample also gained remarkable nitrogen composition thanks to the sizing layer containing urethane segment. Narrow grooves can be seen on the surface of desized CF sample. The smooth surface of desized CF and relatively rougher surface of CF can be clearly observed from SEM micrographs and AFM images of CF samples in Fig. 2.

\subsection{Morphological study}

SEM micrographs of composites are displayed in Fig. 3. It can be confirmed by SEM micrographs that sized CFs dispersed uniformly into ABS phase. This may due

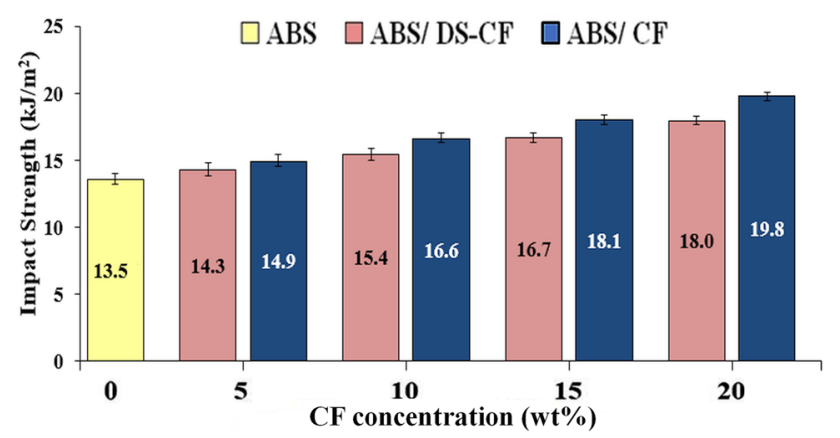

Fig. 5 Impact test data of composites to the improvement of compatibility of CF with $A B S$ matrix by the help of PU-sized surface of CF. Sized CF surfaces were covered by polymer phase and almost no debonding formation was observed for CF filled ABS composites. On the other hand, large gaps were formed between DS-CF and ABS matrix which may stem from the lack of adhesion regarding the inertness DS-CF surface to polar ABS matrix. In the case of CF amount, it can be observed that fibers were oriented well in one direction for $5 \%$ and $10 \%$ CF loading levels thanks to injection molding process. Further addition of CF caused some disorientations of fibers into polymer matrix. These findings from the SEM analysis provide strong evidence for the effect of sizing layer of CF to ABS matrix.

\subsection{Mechanical performance}

The variations of tensile parameters including tensile strength, percentage strain and tensile modulus with respect to CF amount are displayed in Fig. 4. Tensile strength and tensile modulus of unfilled $A B S$ were improved gradually with increase in CF concentration. Composites containing PU-sized CF exhibited approximately $10 \%$ higher tensile strength values compared to that of desized CF. Similarly, ABS/CF composites gave higher tensile modulus than ABS/DS-CF for all of the filling ratios. These results would mean that polyurethane cover at CF surface caused enhancement on adhesion between fiber and ABS phases by reason of interfacial interaction. $R^{2}$ values located in tensile strength and tensile modulus graphs were found to be linear (nearly 1 ) which indicates that increase in these parameters are proportional with the concentration of CF. This also implies that strength and modulus values are predominantly depend on fiber concentration as claimed by Kelly and Tyson equation [6, 35]. Fiber shortening might be carried out with negligible amount during processing thus, it caused no influence for tensile parameters of composites. On the other hand, percent elongation of neat $A B S$ showed sharp reduction after $C F$ inclusions regardless of sizing. This awaited finding is related with the fact that high aspect ratio fiber additions cause drops down in strain of polymeric materials.

Impact strength values are represented as the function of CF content in the Fig. 5. This figure implies that impact strength of neat ABS extended up to higher levels with increase in CF content. DS-CF loaded composites displayed nearly $10 \%$ lower impact strength values with respect to ABS/CF. This may due to better adhesion of sized CF with $A B S$ matrix relative to DS-CF. This behavior can be explained by the formation of stress failures of CF surface with its surrounding ABS matrix. Surface sizing of CF promotes to resistance against deformation thanks to 
Table 3 Shore D hardness parameters of composites

\begin{tabular}{lll}
\hline $\begin{array}{l}\text { CF } \\
\text { Con- } \\
\text { tent } \\
(\%)\end{array}$ & ABS/DS-CF & ABS/CF \\
\hline 0 & $77.4 \pm 0.1$ & $77.4 \pm 0.1$ \\
5 & $78.1 \pm 0.1$ & $78.8 \pm 0.1$ \\
10 & $79.0 \pm 0.1$ & $80.2 \pm 0.2$ \\
15 & $80.1 \pm 0.2$ & $81.4 \pm 0.1$ \\
20 & $81.3 \pm 0.1$ & $82.7 \pm 0.1$ \\
\hline
\end{tabular}

improvement for interfacial adhesion in CF/ABS composite system [36-38].

Shore $D$ hardness values of $A B S$ and its composites are listed in Table 3. CF inclusions raised Shore hardness of unfilled $A B S$ to higher values. Hardness of composites increased steadily with the loading level of CF. Composites involving sized CF displayed higher values compared to desized ones for all concentrations due to have higher load bearing capacity.

\subsection{Thermo-mechanical response}

Storage modulus, loss modulus and $\operatorname{Tan} \delta$ curves as a function of temperature can be seen in Fig. 6. The peak values of loss modulus and Tan $\delta$ curves correspond to glass transition temperature $\left(T_{g}\right)$ of polymeric material. The $T_{g}$ values indicated in Fig. 6 signify to $T_{g}$ of styrene-acrylonitrile (SAN) portion in ABS structure [39]. Composite samples containing DS-CF yielded higher storage modulus values compared to sized CF-filled composites. Relatively higher stiffness of DS-CF with respect to CF may be the reason of this finding since DS-CF inclusions led to compensation of polymer matrix [20]. The highest loss modulus was observed for $15 \%$ CF containing composite. ABS/20 CF composite gave nearly identical loss modulus with $A B S / 15$ CF composite. It is clearly seen from the curves that sized CF additions led to remarkable increase in loss modulus values and $\mathrm{T}_{\mathrm{g}}$ more than DS-CF samples since strong adhesion between two phases promotes restriction of segmental mobility of polymer chains $[40,41]$.

Tan $\delta$ curves in Fig. 6 implies that all of the CF additions caused shifting for $T_{g}$ of neat ABS to the higher temperatures. Improvement of nearly 6 units on $T_{g}$ value of $A B S$ was observed for the highest amount of CF (20\%). DS-CF containing composites exhibited almost identical $T_{g}$ values each other. The shifting of $\mathrm{T}_{\mathrm{g}}$ values are mainly related with the vibration-damping property of the composites as they subjected to constant deformation during the DMA measurements $[42,43]$.
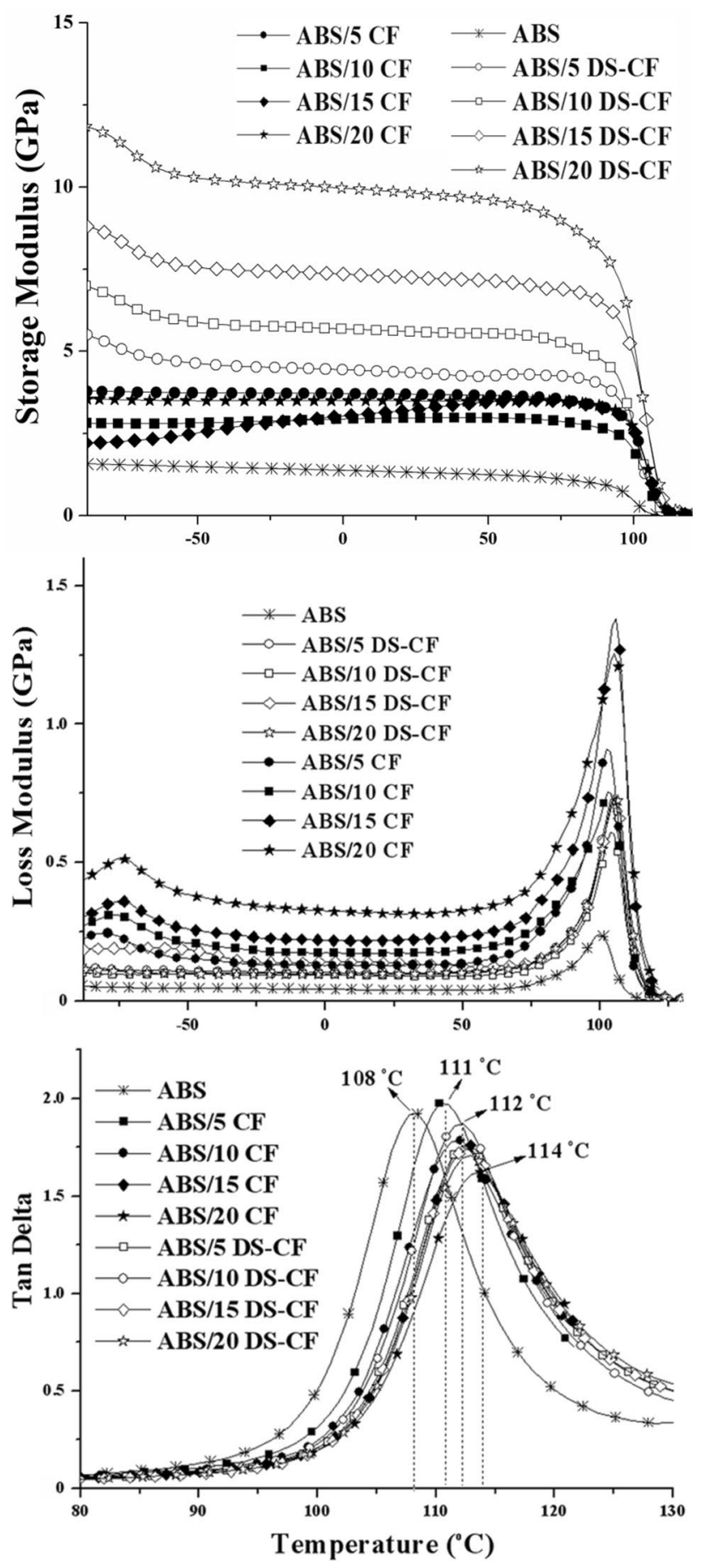

Fig. 6 DMA curves with respect to temperature

\subsection{MFI measurements}

MFI test provides information regarding viscosity and processability of polymers. MFI values of unfilled ABS and composites are given in Fig. 7. As shown in Fig. 7, DS-CF containing composites exhibited slightly lower MFI values with respect to sized CF containing ones. CF inclusions at lower 


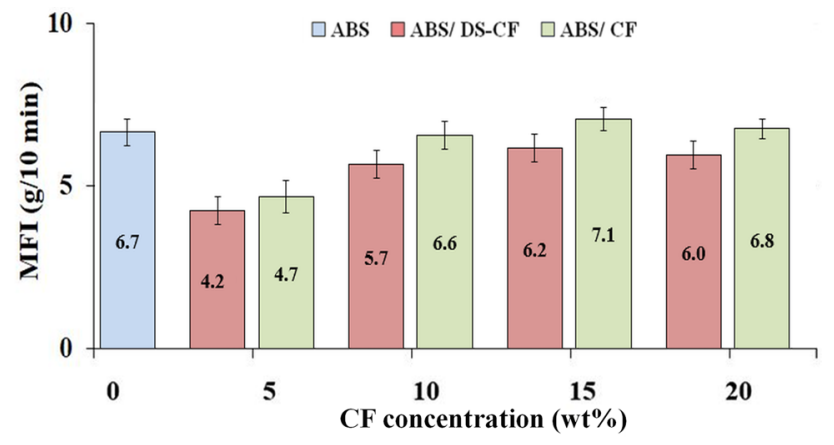

Fig. $7 \mathrm{MFI}$ values of $\mathrm{ABS}$ and composites

loading ratios caused slight decrease in MFI parameters of ABS copolymer. Melt flow behavior of polymer phase was extended with higher CF loadings since high aspect ratio fibers well-dispersed in ABS matrix. Composites displayed narrow MFI range compared to unfilled $A B S$. This result indicates that production of $C F$ reinforced $A B S$ composites can be operated without obvious processing problems in the case of additive manufacturing applications $[44,45]$.

\section{Conclusion}

In this current study, desized and PU-coated short CF were compounded with ABS matrix. Conventional production techniques of polymeric composite materials, melt compounding and injection molding process, were performed due to their cost-effective and practical characteristics. Mechanical, thermo-mechanical, melt-flow and morphological properties of produced composites were postulated. The presence of polyurethane layer was confirmed by surface analysis of CF samples. According to tensile test results, tensile strength and tensile modulus of neat $A B S$ increased with the incorporation of the CF at higher filling ratios in which $10 \%$ and $15 \%$ concentrations displayed higher values. On the other hand, percent elongation of ABS reduced drastically with CF loadings. Impact test revealed that $C F$ additions yielded remarkable improvement for impact strength values of ABS. Sized CF filled composites exhibited relatively higher impact strength than desized CF. Shore hardness of ABS enhanced by incorporation of CF regardless of sizing. DMA analysis showed that loss modulus and glass transition temperature of neat $A B S$ were extended with the addition of $C F$ at higher amounts. Loading levels of $15 \%$ and $20 \%$ CF gave higher storage modulus values among all of the composites. Sized CF inclusions resulted in higher storage modulus and glass transition temperature values with respect to desized ones. CF additions caused no meaningful difference in MFI value of $A B S$ which means that compounding $C F$ with $A B S$ can be taken place with no obvious problems in the case of processing conditions of composites. SEM analysis visualized that sized CF surfaces were covered suitably by polymer matrix which arises from the compatible interfaces between CF and ABS copolymer. Debonding formations were clearly observed between DS-CF and polymer phase due to the lack of adhesion. As an overall conclusion, sized CF samples display better results with respect to desized CF samples. PU-sized CF reinforced composites showed remarkably higher mechanical and thermo-mechanical properties compared to desized CF filled composites. These finding indicated that PU sizing is suitable for ABS/ CF composite system in the future applications of additive manufacturing.

\section{Compliance with ethical standards}

Conflict of interest The authors declare that they have no conflict of interest.

\section{References}

1. Verma D (2020) Carbon fiber reinforced thermoplastics and thermosetting composites. In: Rangappa SM, Parameswaranpillai J, Siengchin S, Kroll L (eds) Lightweight polymer composite structures: design and manufacturing techniques. CRC Press, Florida, pp 267-270

2. Mascia L (1974) The role of additives in plastics. Edward Arnold, London

3. Park SJ (2015) Carbon fibers. Springer, Dordrecht

4. Rahaman M, Khastgir D, Aldalbahi AK (2019) Carbon-containing polymer composites. Springer, Singapore

5. Prashanth S, Subbaya KM, Nithin K, Sachhidananda S (2017) Fiber reinforced composites - a review. J Mater Sci Eng 6(341):2169-2222

6. Moore JD (1973) Acrylonitrile-butadiene-styrene (ABS) - a review. Composites 4:118-130

7. Bucknall CB (1997) Toughened plastics. Applied Science Publishers, London

8. Biron M (2018) Thermoplastics and thermoplastic composites. William Andrew Publishing, New York

9. Mann D, Van den Bos JC, Way A (1999) Automotive plastics and composites. Elsevier Publishing, Amsterdam

10. Rodríguez JF, Thomas JP, Renaud JE (2011) Mechanical behavior of acrylonitrile butadiene styrene (ABS) fused deposition materials. experimental investigation. Rapid Prototyp J 7:148-158

11. Torrado AR, Shemelya CM, English JD, Lin Y, Wicker RB, Roberson DA (2015) Characterizing the effect of additives to ABS on the mechanical property anisotropy of specimens fabricated by material extrusion 3D printing. Addit Manuf $6: 16-29$

12. Forest $C$, Chaumont $P$, Cassagnau $P$, Swoboda $B$, Sonntag $P$ (2015) Generation of nanocellular foams from ABS terpolymers. Eur Polym J 65:209-220

13. Anguita JV, Smith CTG, Stute T, Funke M, Delkowski M, Silva SRP (2020) Dimensionally and environmentally ultra-stable polymer composites reinforced with carbon fibres. Nat Mater 19(3):317-322

14. Dike AS (2020) Improvement of mechanical and physical properties of carbon fiber-reinforced polyamide composites 
by applying different surface coatings for short carbon fiber. J Thermoplast Compos Mater 33(4):541-553

15. Aparna S, Purnima D, Adusumalli RB (2018) Effect of compatibilizer on the properties of polyamide 6 blend based carbon fiber reinforced composites. Fiber Polym 19(6):1335-1346

16. Duchoslav J, Unterweger C, Steinberger R, Furst C, Stifter D (2016) Investigation on the thermo-oxidative stability of carbon fiber sizings for application in thermoplastic composites. Polym Degrad Stabil 125:33-42

17. Rezaei F, Yunus R, Ibrahim NA (2009) Effect of fiber length on thermomechanical properties of short carbon fiber reinforced polypropylene composites. Mater Design 30:260-263

18. Park SK, Jung S, Lee DY, Yoo SH (2020) Effects of electron-beam irradiation and radiation cross-linker on tensile properties and thermal stability of polypropylene-based carbon fiber reinforced thermoplastic. Polym Degrad Stabil. https://doi. org/10.1016/j.polymdegradstab.2020.109301

19. Savas LA, Mutlu A, Dike AS, Tayfun U, Dogan M (2018) Effect of carbon fiber amount and length on flame retardant and mechanical properties of intumescent polypropylene composites. J Compos Mater 52(4):519-530

20. Nie WZ, Li J, Li XZ (2010) The addition of carbon fiber on the tribological properties of poly (vinylidene fluoride) composites. Fiber Polym 11(4):559-564

21. Pinpathomrat B, Yamada K, Yokoyama A (2020) The effect of UV irradiation on polyamide 6/carbon-fiber composites based on three-dimensional printing. SN Appl Sci 2:1518

22. Jiang S, Li Q, Zhao Y, Wang J, Kang M (2015) Effect of surface silanization of carbon fiber on mechanical properties of carbon fiber reinforced polyurethane composites. Compos Sci Technol 110:87-94

23. Love LJ, Kunc V, Rios O, Duty CE, Elliott AM, Post BK (2014) The importance of carbon fiber to polymer additive manufacturing. J Mater Res 29(17):1893-1898

24. Tekinalp HL, Kunc V, Velez-Garcia GM, Duty CE, Love LJ, Naskar AK, Blue CA, Ozcan S (2014) Highly oriented carbon fiberpolymer composites via additive manufacturing. Compos Sci Technol 105:144-150

25. Yang C, Tian X, Liu T, Cao Y, Li D (2017) 3D printing for continuous fiber reinforced thermoplastic composites: mechanism and performance. Rapid Prototyp J 23(1):209-215

26. Huang L, Zhang Q, Wang C (2013) Interface of continuous carbon fiber reinforced ABS. J Mater Eng 3(1):30-34

27. Hull E, Grove W, Zhang M, Song X, Pei ZJ (2015) Effects of process variables on extrusion of carbon fiber reinforced $A B S$. ASME 2015 Conf Proc MSEC2015:9396

28. Quan Z, Larimore Z, Wu A, Yu J, Qin X, Mirotznik M, Suhr J, Byun J-H, Oh Y, Chou T-W (2016) Microstructural design and additive manufacturing and characterization of 3D orthogonal short carbon fiber/acrylonitrile-butadiene-styrene preform and composite. Compos Sci Technol 126:139-148

29. Lee JC, Park DH, Jung HS, Lee SH, Jeong WY, Kim KY, Lim DY (2020) Design for carbon fiber lamination of PMI foam cored CFRP sandwich composite applied to automotive rear spoiler. Fiber Polym 21(1):156-161

30. Ning F, Cong W, Qiu J, Wei J, Wang S (2015) Additive manufacturing of carbon fiber reinforced thermoplastic composites using fused deposition modeling. Compos Part B Eng 80:369-378

31. Zawadzki J (1981) IR spectroscopy investigations of acidic character of carbonaceous films oxidized with $\mathrm{HNO} 3$ solution. Carbon 19(1):19-25

32. Dogan SD, Tayfun U, Dogan M (2016) New route for modifying cellulosic fibers with fatty acids and its application to polyethylene/jute fiber composites. J Compos Mater 50(18):2477-2485

33. Park SJ, Kim BJ (2005) Roles of acidic functional groups of carbon fiber surfaces in enhancing interfacial adhesion behavior. Mater Sci Eng A 408(1-2):269-273

34. Severini F, Formaro L, Pegoraro M, Posca L (2002) Chemical modification of carbon fiber surfaces. Carbon 40(5):735-741

35. Kelly A, Tyson AW (1965) Tensile properties of fibre-reinforced metals: copper/tungsten and copper/molybdenum. J Mech Phys Solids 13(6):329-350

36. Sato N, Kurauchi T, Sato S, Kamigaito O (1991) Microfailure behaviour of randomly dispersed short fibre reinforced thermoplastic composites obtained by direct SEM observation. J Mater Sci 26(14):3891-3898

37. Chotirat L, Chaochanchaikul K, Sombatsompop N (2007) On adhesion mechanisms and interfacial strength in acrylonitrilebutadiene-styrene/wood sawdust composites. Int J Adhes Adhes 27(8):669-678

38. Ozkoc G, Bayram G, Bayramli E (2008) Impact essential work of fracture toughness of ABS/polyamide- 6 blends compatibilized with olefin based copolymers. J Mater Sci 43(8):2642-2652

39. Suzuki M, Wilkie CA (1995) The thermal degradation of acryIonitrile-butadiene-styrene terpolymei as studied by TGA/FTIR. Polym Degrad Stabil 47(2):217-221

40. Sinha S, Okamoto K, Okamoto M (2003) Structure-property relationship in biodegradable poly (butylene succinate)/layered silicate nanocomposites. Macromolecules 36(7):2355-2367

41. Tayfun U, Dogan M, Bayramli E (2017) Polyurethane elastomer as a matrix material for short carbon fiber reinforced thermoplastic composites. Anadolu Univ J Sci Technol A Appl Sci Eng 18(3):682-694

42. Turk DA, Brenni F, Zogg M, Meboldt M (2017) Mechanical characterization of 3D printed polymers for fiber reinforced polymers processing. Mater Design 118:256-265

43. Jyoti J, Singh BP, Arya AK, Dhakate SR (2016) Dynamic mechanical properties of multiwall carbon nanotube reinforced $A B S$ composites and their correlation with entanglement density, adhesion, reinforcement and C factor. RSC Adv 6(5):3997-4006

44. Wang S, Capoen L, D'hooge DR, Cardon L, (2018) Can the melt flow index be used to predict the success of fused deposition modelling of commercial poly(lactic acid) filaments into 3D printed materials? Plast Rubber Compos 47:9-16

45. Turner BN, Gold SA (2015) A review of melt extrusion additive manufacturing processes: II. materials, dimensional accuracy, and surface roughness. Rapid Prototyp J 21:250-261

Publisher's Note Springer Nature remains neutral with regard to jurisdictional claims in published maps and institutional affiliations. 